\title{
Application of Carbon Nanotube (CNT) to Photosensitive Diazo /PVA Resist (2) - Conductivity
}

\author{
Kieko Harada ${ }^{1}$, Masahiro Nakada ${ }^{1}$, Kiyomi Matsuda ${ }^{2}$, \\ Shigeru Takahara ${ }^{3}$, Katsuyoshi Hoshino ${ }^{3}$ and Kazuyuki Sugita ${ }^{3}$ \\ 1 Education Center, Chiba Institute of Technology, \\ 2-1-1 Shibazono, Narashino-shi,Chiba 275-0023 JAPAN \\ 2 College of Industrial Technology, Nihon University, \\ 1-2-1 Izumi Narashino-shi, Chiba 275-8575 JAPAN \\ 3 Faculty of Engineering, Chiba University, \\ 1-33, Yayoi-cho, Inage-ku, Chiba 263-8522 JAPAN
}

\begin{abstract}
Electro-conductivity of a thick Diphenylamine-4-diazonium sulfate/formaldehyde condensate/polyvinyl alcohol (DSR/PVA) resist layers increased by the incorporation of multi-walled carbon nanotube (CNT) and fulleren $\mathrm{C}_{60}$ (weight ratio of $\mathrm{CNT}$ or $\mathrm{C}_{60}$ to DSR $=1.00: 1 \sim 3.00: 1$ ). Conductivity of DSR/PVA film with CNT was one order larger than that with $\mathrm{C}_{60}$. The larger conductivity depends on the charge leakage through the network or thread-bundle structure of multiwalled CNT. Conductivity of shorter CNT $(3 \sim 20 \mathrm{~nm})$ was larger than that with long CNT (40 70 $\mathrm{nm})$. The $\sigma$ values for the thin films $(6 \mu \mathrm{m})$ were ca. two times larger than those for the thick films ( $12 \mu \mathrm{m}$ ). Photo decomposition of DSR/PVA resist with CNT was accelerated reductively by the electrons evolved from CNT, absorbing light energy. Electron rich characteristics of CNT may play an important role in the enhancement of electric conductivity and photo decomposition rate.

Keywords: photosensitive diazo compound, multi-walled nanotube (CNT), $\mathrm{C}_{60}$, conductivity, Photodecomposition
\end{abstract}

\section{Introduction}

The para-substituted benzene diazo compounds (SBD) with electron-donating (DSBD) are used as photo acid generators for micro resists [1], photosensitive emulsions for the screen printing resist [2], and contrast enhancement lithographic (CEL) materials. SBD with electron-withdrawing substituents (WSBD) was used for acidic initiators for polymerization of UV-curing coatings. The photo decomposition of a diphenylamine-4-diazonium sulfate/ formaldehyde condensate/polyvinyl alcohol resist (DSR/PVA resist) was accelerated by mixing with carbon nanotube (CNT) as well as polyethylene glycohol-300 (PEG300), but not with fulleren $\left(\mathrm{C}_{60}\right)$ [3-5]. Etching durability of a positive-working electron beam resist is reported to be improved with $\mathrm{C}_{60}$ [6]. We previously reported the hardness of a DSR/PVA resist layer after UV irradiation increased by addition of CNT [7]. There are many reports on application of single-walled carbon nanotubes (SWNT) to electronic devices [8,9]. Parabromobenzene diazocompound tetrafluoroborate (BrBD) which selectively reacts with metallic
SWNT is used for separation of a metal SWNT from the mixture with semiconductor SWNT [10].

In the present investigation, conductivity of thick DSR/PVA resist films containing $\mathrm{C}_{60}$ and CNT is measured for testing the possible application to wiring materials.

\section{Method}

\subsection{Materials}

The conventional photosensitive diazo resin, DSR and PVA emulsion for screen printing, were purchased from Murakami Screen KK. The additives used were $\mathrm{C}_{60}$ from Aldrich Co., Ltd. and the multi-walled carbon nanotubes (CNT) with diameter of 3 20, 20 50, 40 70 nm from Micro phase Co., Ltd., which were lower price, instead of the single-walled nanotubes.

Coating solutions of the resist were prepared by dissolving $0.6 \mathrm{~g}$ of the diazo compound in $100 \mathrm{~g}$ of the matrix PVA-emulsion in water together with the additives. The resist layers (PVA films) for photodecomposition were coated onto glass plates to a 
thickness of 6,12 and $15.4 \mu \mathrm{m}$. UV spectra of the films were measured with a Shimadzu UV-1600 PC spectrophotometer.

\subsection{Measurements}

Resist layer (DSR/PVA) films were irradiated by a Sunhatoya Chibi Light Model BOX 1 with fluorescence light (FL-6BL). The incident energy was $2.2 \mathrm{~mW} / \mathrm{cm}^{2}$. The remaining ratio of DSR was measured after irradiation without development by water. Conductivity of films after irradiation and development by water, was measured by the fourpoint probe method with a Mitsubishi Chemical Analytech Loresta GP MCP-T600 and MCPTPO6P probe.

\section{Results and Discussion}

3.1 Conductivity of thick DSR/PVA resist films with CNT or $\mathrm{C}_{60}$.

Relations between conductivity $\sigma$ at roomtemperature and weight ratio of CNT or $\mathrm{C}_{60}$ to DSR are shown in Fig.1. Conductivity of thick DSR/PVA resist films with CNT or $\mathrm{C}_{60}$ were larger than that without additives, and became constant in the range of weight ratio, CNT : DSR $=1: 1 \sim 3: 1$. and $\mathrm{C}_{60}=1: 1 \sim 4: 1$, respectively. Conductively of DSR with CNT was about one order larger than that with $\mathrm{C}_{60}$. It is considered that the larger conductivity depends on the charge leakage through the network or thread-bundle structure of multiwalled CNT. Conductivity of DSR with CNT decreased at weight ratio of $4: 1$, which may be caused by poor dispersion of CNT in the PVA film.

\subsection{Photo-decomposition of DSR/PVA resist films} with $\mathrm{CNT}$ or $\mathrm{C}_{60}$

The color of CNT and $\mathrm{C}_{60}$ is black and dark violet, respectively, and retard photo-decomposition of diazo compound in the resist layer by the shielding effect. The residual DSR in a DSR/PVA film containing $\mathrm{CNT}$ or $\mathrm{C}_{60}$ was measured by UV spectrometry after irradiation for $1 \mathrm{~min}$ without washing-out with water. The remaining ratios of the compounds were calculated from the absorption at $\lambda$ max, and are plotted against CNT or $\mathrm{C}_{60}$ content as shown in Fig.2.

The remaining ratios of DSR in the films with CNT $(0.25: 1 \sim 1.0: 1)$ were smaller than that in

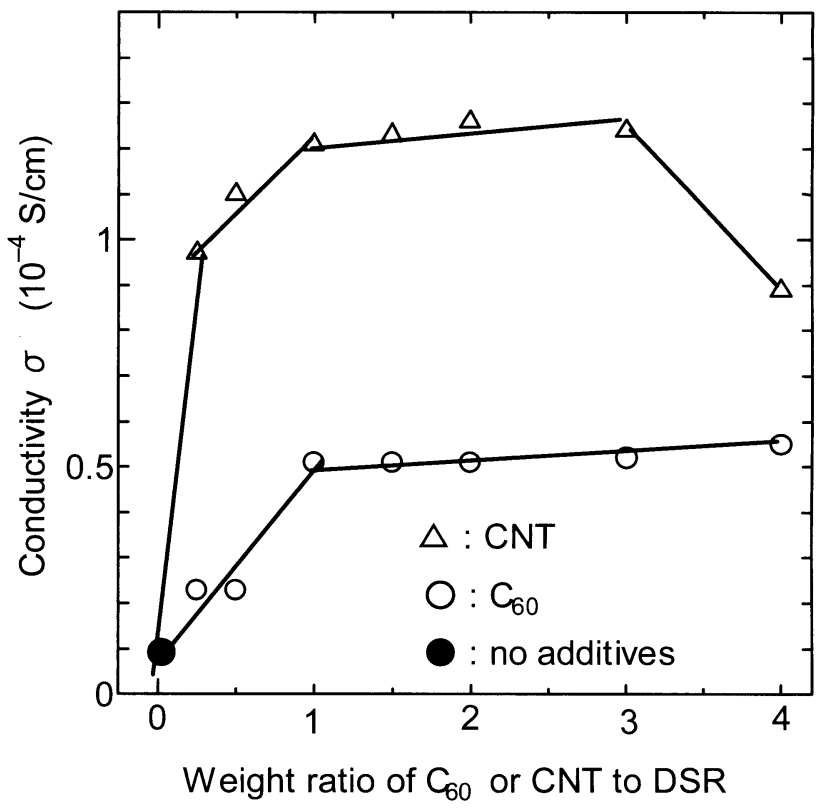

Fig. 1 Electric conductivity of DSR/PVA films and relation to $\mathrm{C}_{60}$ (open circles) or CNT (open triangles) content. Film thickness: $15.3 \mu \mathrm{m}$, Room temperature.

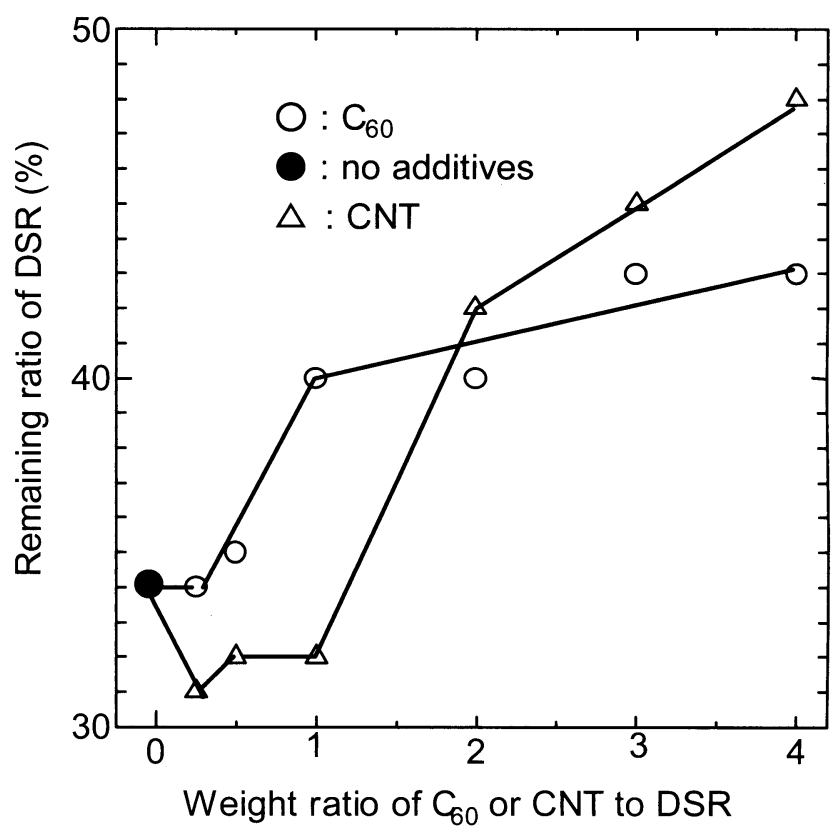

Fig. 2 Photo-decomposition of DSR/PVA films as a function of $\mathrm{C}_{60}$ or CNT content. After 1-minute irradiation. Film thickness : $15.3 \mu \mathrm{m}$ 


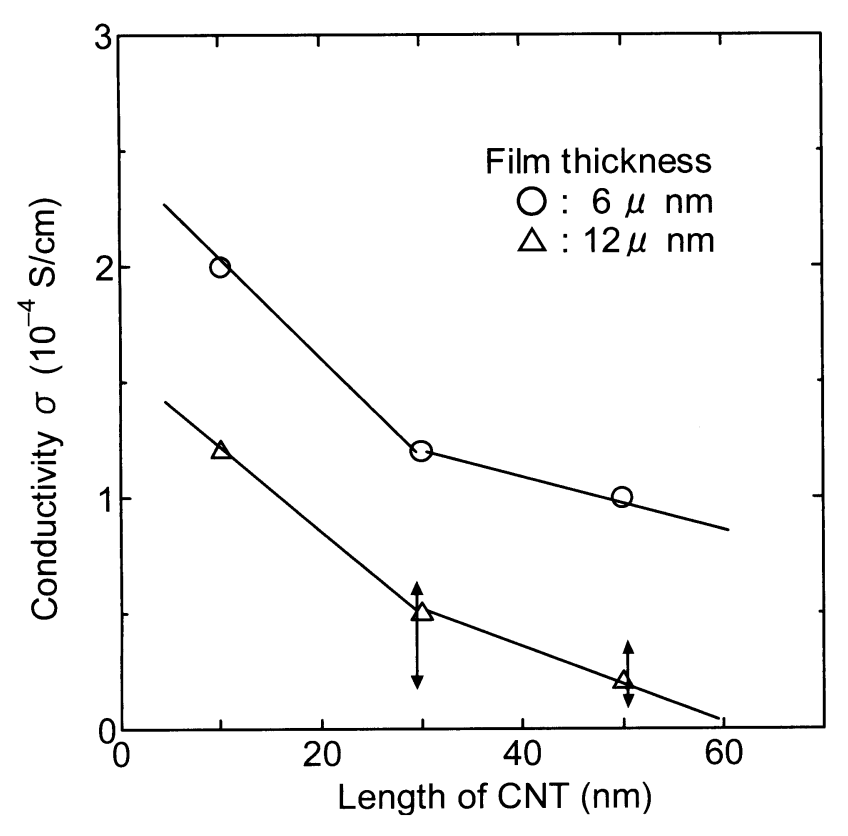

Fig. 3 Electric conductivity of DSR/PVA film with various size of CNT

Weight ratio, DSR : CNT $=1: 1$, Room temperature

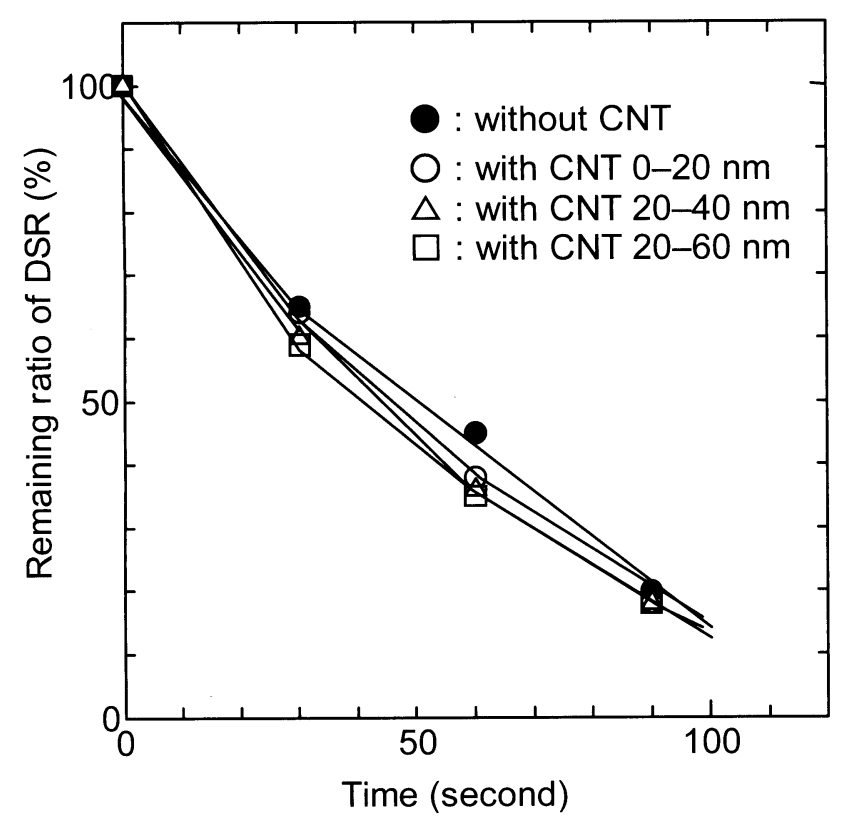

Fig. 4 Photodecomposition of DSR/PVA films with various size of CNT

Weight ratio, DSR : $\mathrm{CNT}=1: 1$, the film without CNT, which means accelerated photo decomposition under reduced incident radiation intensity caused by the shielding effect of CNT It is considered that the photo decomposition is accelerated reductively by the electrons evolved from CNT, absorbing light energy.

3.3 Effect of CNT length for conductivity of DSR/PVA resist films

Relation between conductivity $\sigma$ and length of CNT are shown in Fig. 3. Conductivity with shorter CNT (3 20 nm) was larger than that with longer CNT $(40 \sim 70 \mathrm{~nm})$. Films with long CNT showed light scattering due to the poor dispersion of long CNT. The $\sigma$ values for the thin films $(6 \mu$ $\mathrm{m})$ were ca. two times larger than those for the thick films $(12 \mu \mathrm{m})$. This can be explained by assuming that the percolation threshold depends on the film thickness and that its value decreases with a decrease in film thickness.

3.4 Effect of CNT length for photodecomposition of DSR/ PVA resist films

It was observed that photo decomposition of films was accelerated by the incorporation of CNT. However, no effect of CNT length was observed on the photodecomposition rate. Additionally, film transparencies were little affected by the incorporation and the size of the CNT materials.

\section{Conclusion}

Electric conductivity and photodecomposition rate of the DSR/PVA resist layers were increased by the incorporation $\mathrm{C}_{60}$ and $\mathrm{CNT}$ (weight ratio of $\mathrm{C}_{60}$ or CNT to DSR $=1.00: 1 \sim 3.00 \sim 1$ ). Electron rich characteristics of CNT may play an important role in the accelerated electric conductivity and the enhanced photodecomposition rate. Additionally, the enhancement in electric conductivity with the incorporation of $\mathrm{C}_{60}$ and $\mathrm{CNT}$ may be applied to electrically conductive materials with good optical transparency for the flexible electronics of next generation.

\section{Acknowledgment}

The authors thank Assoc. Prof. Yohko Hanzawa and Tetsuyuki Taniai of Chiba Institute of Technology for their helpful suggestions. 


\section{References}

1. K.Harada, M.Kushida, K.Saito, K.Sugita and H.Iida, "Micro- and Nanopattering Polymers" H.Ito, E.Reichmanis, O.Naramasu and T.Ueno, eds., ACS Symp. Ser.706, Amer. Chem. Soc., Washington, D.C., 1998, pp. 126-133

2. K.Harada, M.Kushida, K.Saito, K.Sugita and H.Iida, J. Imaging Sci. and Technol., 46, (2002) 159.

3. K.Harada, M.Kushida, S.Miyagawa, S.Takahara and K.Sugita, J.Photopolym.Sci.Technol., 18, (2005) 187.

4. K.Harada, T.Taniai, M. Nakada, H.Hamana and K. Sugita, J.Photopolymer Sci. Technol., 20, (2007) 309.

5. K.Harada, T.Taniai, M.Nakada, H.Hamana and
K.Matsuda, S. Takahara and K.Sugita, J. Photopolymer Sci. Technol., 21,(2008) 59

6. T.Shibata, T.Ishii, H.Nozawa and T.Tamamura, Jpn. J.Appl. Phys., 368 (12B), (1997) 7642.

7. K.Harada, T.Taniai, M.Nakada, H.Hamana, K. Matsuda, S. Takahara and K. Sugita, J. Photopolym. Sci. Technol., 22 (2009), 347

8. Z.Wu, Z.Chen, X.Du, J.J.Logan, J.Shippel, M. Nikolu, K. Kameras, J.R.Renols, D.B.Tanner,

A.F.Hebard and A.G.Rinzler, Science, 305, 1273, (2005) 1273.

9. E.Bekyarova, M.E.Itkis, N.Cabrera、B. Z. Hao, A.Yu, G.Gao and R.C. Haddon, J.Am.Chem.Soc. 127, (2005) 5990.

10. C.J. Wang, Q. Cao, T.Ozel, A. Gaur, J.A. Rogers and M. Shim, J. Am. Chem. Soc. 127 (2005) 11460 